\title{
マイクロ波による繊維含有率の測定
}

\author{
工業技術院製品科学研究所四方田重昭 -小野昌孝 \\ 牧広
}

THE MEASUREMENT OF FIBER CONTENT IN FRP BY MICROWAVE METHOD

By Shigeaki Yomoda, Masataka Ono and Hiroshi Maki

(Industrial Products Research Institute, AIST, MITI, 4-21-2 Shimomaruko Ota-ku Tokyo Japan)

\begin{abstract}
A method was devised to determine the fiber content in Fiber Reinforced Plastics (FRP) by the microwave technique and the result was as follows:

The fiber content in Carbon FRP (CFRP) and Glass FRP (GFRP) could be determined from the transmission loss of microwave with a high accuracy. The relation between the fiber content and the transmission loss of microwave in the case of GFRP differed from that of CFRP. The fiber content of CFRP having more than 10 plies of carbon cloth could not be measured by this technique due to the larger transmisșion loss of CFRP.
\end{abstract}

The fiber content could be measured by this method when the resin in FRP was not only solid, but also in liquid.

(Received, March 28, 1975)

\section{1. 通論}

䋐維强化プラスチック(FRP)の強度，力学特性は， その中に含まれる瀻維量に密接に関係している。この

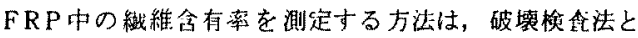
非破颢検查法にわけら㧈る。

従来，主として行なわ机てきたのは破墩検查法”であ る。この方法は，FRP中の樹脂を分解または燃焼する ことにより㵶維成分だけとし，この重鼠を測定すること により，緎維含有索を求めるものである。緎維としてか ラス緎維を用いたFRPは，加熱炉内の樹脂の分解㛙失 によって比較的精度よく，簢単に測定できる。

しかし，カーボン瀻維を用いた FRPでは，加熱によ り，カ一术ン瀻維の酸化分解括よび樹脂が残查として䄉 維間に残る可能性がある。

大形成形物であるクーリングタワー，船，自動車のボ デー，汾槽等の成形加「に括いては，加工による䋐維含 有率のむら，㵶稚の方向性，さらに鼠近広く用いられて いる SMC(Sheet Molding Composite)では成形 加工中における絏維の流扎等が問題となっているか力，破

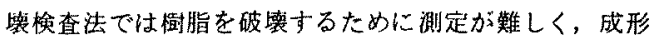

加て中におうりる連続測定および完成品についての製品検 查等の測定はできない。したがって非破壊㭘查法の確立 が望まれている。

非破壞検相法として著者等 ${ }^{8)}$ は，超音波による測定方 法を険討してきた。超音波による测定法は，FRP中を 伝わる超㫮波の音速を剆定することにより，織維含有率 怙よび封脂の状態を求めるものである。しかし，便用寸 る超音波の波長と繊維直径との関係，䋐維含有率が低い 場合，音速の変化が少ないことおよび緎維含有率を算出 する近似式 ${ }^{3)}$ が幾種類むあり，確立されていない等の問 题点を持っている。そこで, 非破壊测定法としてマイク 口波を用いて测定する方法について検討を行なった。

\section{2. 実 笑}

実験に用いたFRPの樹脂はエボキシ栰脂(メピュー ト828，三菱油化製)，硬化郕はシェチレントリアミン (DETA，分子量103)を使用した。

䋐維としてガラスクロス（ECR860，日東紡 KK）拈 よびカーボンクロス(トレカ2002，東レKK)を用いた。 このカーボンクロスは、横系としてガラス維維が，4本 / cm使用されている。 


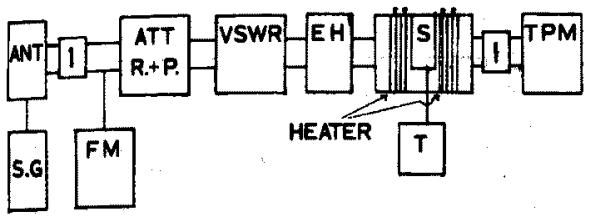

Fig. $14 \mathrm{GHz}$ Microwave Apparatus for measuring transmission loss of specimen

S.G: signal generator ANT: antenna

FM: frequency measurement

ATT.R.+P.: rough attenuatortprecise attenuator VSWR: voltage standing wave ratio measurement EH: EH tuner for maching S: specimens holder $\mathrm{T}$ : thermo couple $\mathrm{I}$ : isolator TRM: thermister power meter

These microwave elements (ANT, I, FM, TPM, etc) were coupled with a wave guide. $4 \mathrm{GHz}$ microwave were radiated in the wave guide by an antenna of klystron tube, passed the wave guide, the elements and specimen, and its receiving power were measured by a thermister power meter and a digital volt meter. Its receiving power and standing wave were changed by specimens.

瀑度湘定は，熱電詨アルィル・クロメル $(\mathrm{Ar}-\mathrm{Cr}) を$ 用Wた。

樹脂の硬化測定法 TBA ( Torsional braid Analysis 记用䉓気 KK) を使用した。

実駼に用いたマイクロ波測定装置は図1に示した。周 波数は $4 \mathrm{GHz}\left(4 \times 10^{9} \mathrm{~Hz}\right)$ である。その発振は，クライ ストロン管㧍よび同軸導波管变換器により，導波管内に マイクロ波を発射させ行なった。そして発射されたマイ ク口波は, 周波数測定装置, 定在波測定装置, 减衰器(普 通級および直読型精密級)等を経て，試料入入射する。 試料を透過した波の電力はサーもェレクトリック電力 計とデシタル電纴計により測定する。

発射電力は减衰器により，60 db讫可变することがで きる。試料表面からのマイク口波の反射および反射波に よる定在波は，定在波測定装監により湘定を行なった。 周波数測定の確度は土 $1 \mathrm{MHz}$ である。発振部扝よび電力 測定部は，単向管を接続し他の影響を受けないようにし た(いずれも帛田理化 KK)。

\section{3. 考 察}

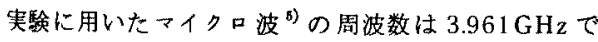
ある。マイクロ波は，低周波数の電磁波であるラジオ電 波と高周波数の赤外線，可視光線の中間に位圆している。

FRPのような複合材料の測定に使用する場合，ラシ 才電波は材料中を透過する。しかし，波長が長く，透過 電力，反射波，波の位相の測定が困難である。また，赤 外線および可視光線は，透明な材料を用いる場合湘定で きるが，一般に不透明な複合材料では透過せず測定でき

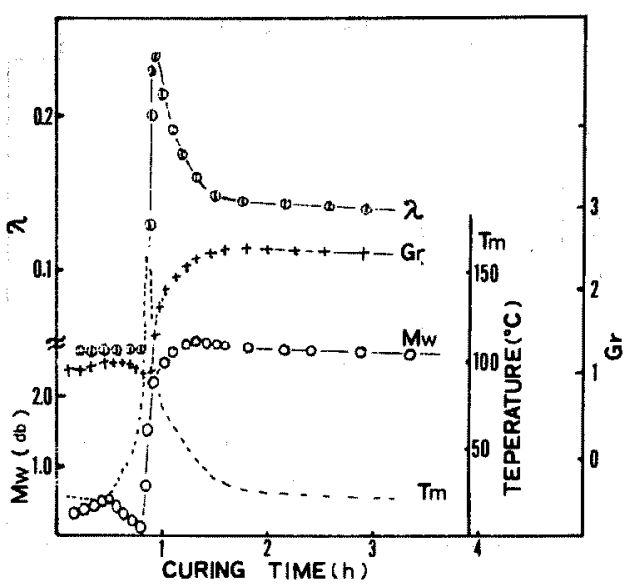

Fig. $2 \mathrm{Gr}, \lambda$ and $\mathrm{Mw}$ vs curing time of epoxy resin Gr: relative modulus $\lambda$ : logarithmic decrement $\mathrm{Mw}$ : transmission power of microwave

$\mathrm{Gr}_{\mathrm{r}}$ and $\lambda$ of epoxy resin were measured by torsional braid analysis (TBA). Gr and $\mathrm{Mw}$ were increased by cross linking, while $\lambda$ had peak at the gel point of epoxy resin, because $\lambda$ corresponded to energy loss in the resin.

ない。したがって，金属以外は，材料中を透過するマイ ク口波を用いて象験を行なった。マイク口波はラジオ 電波に比べ，波長が短いため，云達する時の方向性が良 く，電力測定が容易である。さらに，村料中を透過した 波の位相，振偪の变化が測定できる。ただし，金属扔上 び云道性物質を含む材料では，その量にもよるが，表面 でマイクロ波が庈射するため測定することが困難となる。

FRP 試料に用いたエポキシ樹脂の硬化の測定および マイクロ波による测定とTBA 法による測定との対空関 䌽を調心゙た。その結果老図 2 に示した。マイクロ波の樹 脂の硬化に伴う透渦量の変化は, 硬化測定に広く用いら れているTBA 法による相対岡性率 (Gr) の変化に対庍 している。赤外線を利用した測定は，森本等 ${ }^{6}$ により行 なわれている。低周波数領域では，誘電率による測定が 行なわれて抢り，いずれも，マイクロ波による測定と良 い対応を示している。

試料に入射するマイク口波は，一方向に進む進行波で あり，その電力は変化しない。しかし，試料表面におい て入射波の一部分が反射され，反射波が生じる。そして この反射波が入射波と干涉して定在波を形成する。反射 波は，試料の状態により変化する。したがって定在波も 変化する。樹脂の硬化に伴う定在波の変化を測定し図 3 に示した。図中の波長は䄪 $10 \mathrm{~cm}$ でる。尊波管内の波 長は, 自由空間に扔ける波長, $4 \mathrm{GHz}$ の場合 $7.5 \mathrm{~cm}$ と翼 り，計算値では $9.8 \mathrm{~cm}$ になる。凬波数は一定であるが, 


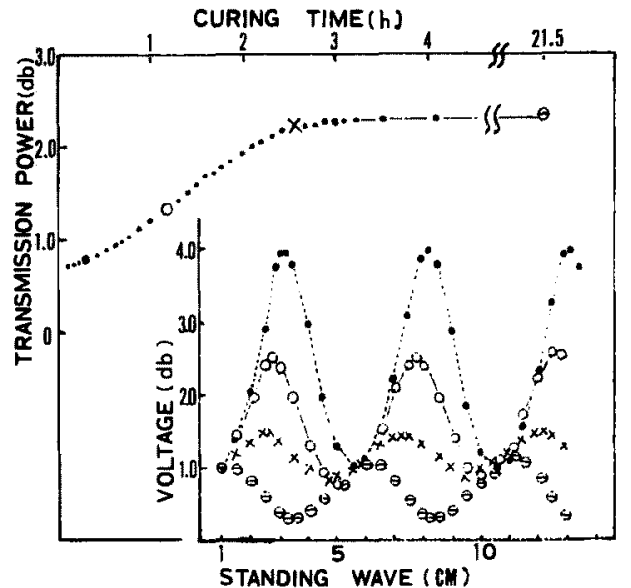

Fig. 3 Standing wave and Mw transmission power vs curing time of epoxy resin

$\begin{array}{cc} & \text { standing wave at a time of curing } \\ :: & 0 \mathrm{~min} \\ 0: & 1 \mathrm{~h}+10 \mathrm{~min} \\ \times: & 2 \mathrm{~h}+30 \mathrm{~min} \\ \theta: & 2 \mathrm{l}+31 \mathrm{~min}\end{array}$

Mw transmission power and standing wave were changed by curing of epoxy resin.

The amplitude and phase of standing wave were changed by curing, but frequency was not changed.

The wave length of micro wave in wave guide and resin was longer than that in air. It was $9.8 \mathrm{~cm}$ in wave guide and $7.5 \mathrm{~cm}$ in air.

樹脂の状態の変化に伴い，殿射波が变化するため，定在 波の位相抢よび振幅值が変化している。このことから， マイク口波を用いて測定する場合，透過量，位相，振幅 值”の変化を使用することができる。しかし，反射波に よって生ずる定在波の位相，振幅值は，試料表面または 表面に近い部分に影膘されるので，FRPの上うな複合 材料の測定には適さない。

ガラスクロスを用いてFRP を製作し，透過電力を湘 定した結果を図4に示した。

ガラスクロスを入れた F RP 試料においても図3と同 様に樹脂の状態変化を透過量の変化として測定すること ができるしかし、ガラスクロスの含有量が变化しても その差は非常に小さい。定在波の变化も图 3 のそ机と同

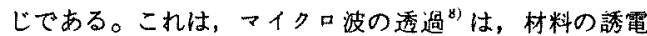
率に影響され，ガラスの誘電率が $4.0 \sim 5.0(1 \mathrm{MHz})$ ， メ ポキシ樹脂の誘電率が $3.3 \sim 4.0(1 \mathrm{MHz})$ と差が小さい ためと思われる。試料の厚さが $20 \mathrm{~mm}$ と厚く，図 3 の定 在波湘定図では $20 \mathrm{~mm}$ は数 $\mathrm{db}$ の变化に相当している。 そのために繥脂の変化による透過量の差が，䋐維含有量 による差より大きく測定された。

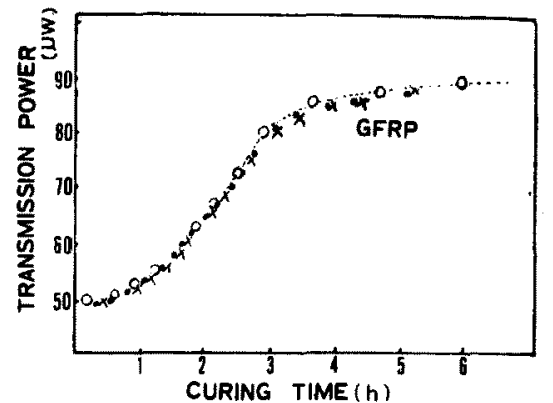

Fig. 4 Microwave transmission power vs curing time of GFRP

$O$ : glass cloth 140 plies; fiber weight content $21 \%$

$\begin{array}{lll}-: & 60 & 9 \% \\ x: & 30 & 3 \%\end{array}$

The thickness of GFRP specimen is $20 \mathrm{~mm}$.

The Mw transmission power was increased by curing of epoxy resin in GFRP. The discrepancy of Mw transmission power of FRP having different glass fiber weight content was very small.

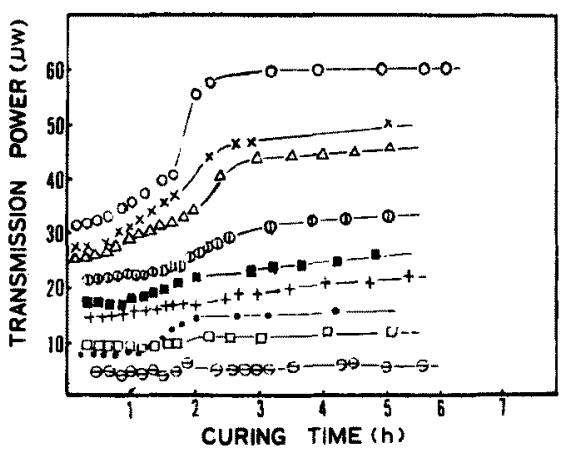

Fig. 5 Microwave transmission power vs curing time of CFRP

$O$ : carbon cloth 1 ply fiber weight content $0.6 \%$

\begin{tabular}{|c|c|c|c|}
\hline$\times$ : & " & 2 plies & $1.2 \%$ \\
\hline$\therefore$ & ". & $3 "$ & $1.5 \%$ \\
\hline (1) & " & $4 "$ & $2.2 \%$ \\
\hline a & " & $5 "$ & $2.6 \%$ \\
\hline+ & " & $6 "$ & $2.9 \%$ \\
\hline & " & $7 "$ & $3.3 \%$ \\
\hline$\square$ & " & 8 & $3.9 \%$ \\
\hline$\theta$ & " & $10^{\prime \prime}$ & $4.7 \%$ \\
\hline
\end{tabular}

The transmission power was increased by curing of epoxy resin in CFRP. The difference of transmission power by curing of epoxy resin depended on carbon fiber content in CFRP.

The transmission power of CFRP having above 10 plies was not changed. 
次にカーポソクロスを用いて FRP 製作した。そし てその中の樹脂が，硬化に伴い倠状から固体まで变化し， それによるマイクロ波の透過䑁の变化を連続的に湘定し た。その結果を図5に示した。カーボンクロスの量によ る透過量の差が; 樹脂の液状扔よび固体の状態において も測定できる。特にカーポンクロスの多い試料(カーボ ンクロス 10 枚入で，絨維重量含有率は $4.7 \%$ である。 では，樹脂の状熊の違いによる透過量の差は非常に小さ い。したがって，FRPの成形加工の度合を知るための 樹脂のゲル化の測定ができない。

すなわち、ガラスクロスと異なり，カーポンクロスは， その量を增加すると，マイク口波の透過量が減少する。 これは,カーボン瀻維は導体に近く，その抵抗は瀻維方 向で， $0.005 \Omega / \mathrm{m}$, 瀻維に直角力向で， $5.7 \Omega / \mathrm{m}$ であ るため，マイク口波は，カーボンクロスに上り反射され るためと思われる。

图 5 に称いて樹脂の硬化時間 30 分の液状と架橋反応 がほぼ終了し，硬化した 5 時間の時点における，カ一ボ

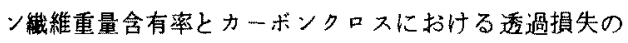
関俰を図6に示した。樹脂が硬化した時点では，カーボ

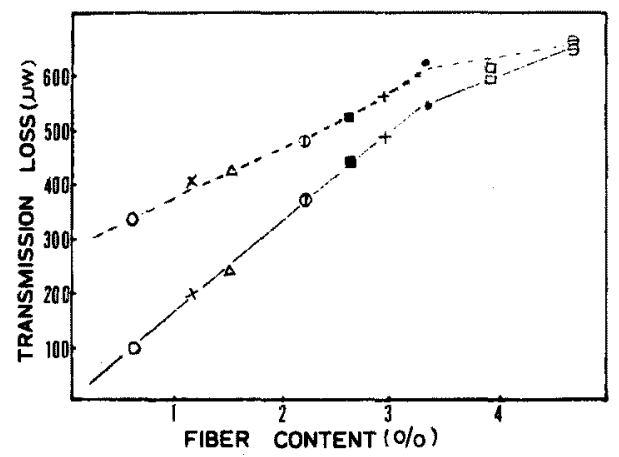

Fig. 6 The microwave transmission loss vs carbon fiber weight content in CFRP

0 : carbon cloth 1 ply fiber weight content $0.6 \%$

\begin{tabular}{|c|c|c|c|c|c|}
\hline x : & " & & blies & " & $1.15 \%$ \\
\hline$\Delta:$ & " & 3 & $n$ & ". & $1.50 \%$ \\
\hline (1) : & “ & 4 & " & $"$ & $2.20 \%$ \\
\hline 口 : & " & 5 & $"$ & " & $2.63 \%$ \\
\hline+ : & " & 6 & " & ." & $2.92 \%$ \\
\hline - : & " & 7 & " & ." & $3.31 \%$ \\
\hline 口: & " & 8 & ". & ", & $3.92 \%$ \\
\hline$\theta:$ & " & 10 & ". & $"$ & $4.70 \%$ \\
\hline
\end{tabular}

The full line and dotted line are relations between microwave transmission loss of CFRP and carbon fiber weight content at $5 \mathrm{~h}$ and $30 \mathrm{~min}$ after curing was started, respectively.

The transmission loss of CFRP was increased as the carbon fiber weight content was increased.

The thick ness of CFRP was $20 \mathrm{~mm}$.
ンクロス 7 枚入りCFRP，緎維重量含有率 $3.3 \%$ 以下で は, 繊維重量含有率と透過損失は直線関係が成立してい る。それ以上の瀻維含有繁では，カーポンクロスによる マイクロ波の反射のため，直線よりはずれる。

硬化開始より 30 分経過した時点での関俰も，絩維重 量含有率が低い試料では直線関保が成立する。しかし， 直線の傎きは，5時間のそれとは珙なる。こ机は，樹脂 が液状の場合，その透過損失が硬化した試料のそれに比 べて大きいためと思われるが明らかでない。

カーボンクロスを用いたCFRPの透滑損失は，主と してクロスによるマイクロ波の反射によるため，瀻維含 有率の測定は, CFRPに入っているクロスの枚数により 制限を受ける。

緎維重量含有索を上げるため，試料の厚さを1/10の $2 \mathrm{~mm}$ にしたFRPを製作し，その透過損失と織維重量 含有率の関係を测定した。その結果を図７に示した。図 7 に示した各試料の密度のと密度より求めた䄉維重量含 有率扰よ゙がラス，カーボンクロスのそれぞれの枚数を 表1に示した。

瀻維重量含有率が增加するとGFRPの透過損失は减 少するが，CFRPの透過損失は增加する。そしてその変 化の度合は，CFRPの变化が，GFRPのそれに比較し て約 40 倍大きい。特にGFRPは変化が小さいのでサー

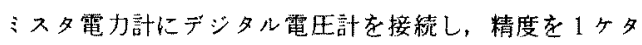

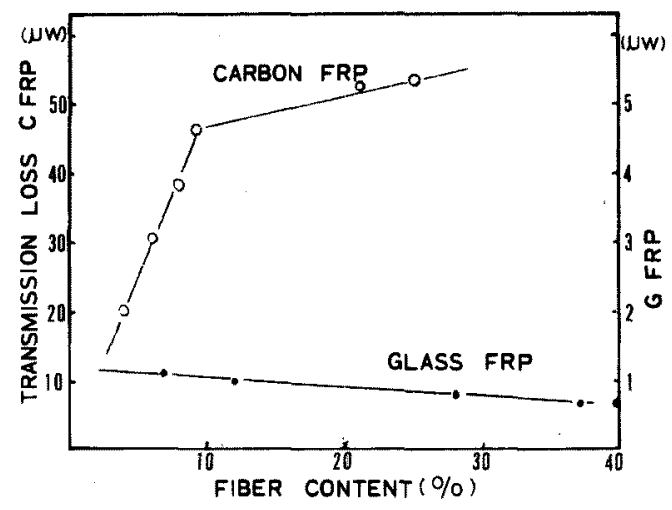

Fig. 7 The microwave transmission loss vs carbon and glass fiber weight content in FRP

The lines (CFRP, GFRP) are relation between microwave transmission loss of FRP and the fiber weight content in FRP.

The higher the fiber weight content, the more the transmission loss of CFRP, but on the contrary in case of GFRP, the higher the fiber weight content, the less the transmission loss, because the microwave was reflected by carbon cloth which had low electric resistivity and the dielectricity of glass was higher than epoxy resin. 
Table 1 The density $\rho$, the quantity of carbon cloth and glass cloth, and the fiber weight content of FRP

The fiber weight content of CFRP and GFRP was determined from the density of FRP.

The thickness of FRP was $2 \mathrm{~mm}$.

\begin{tabular}{|c|c|c|c|c|c|c|c|}
\hline & $\rho\left(\mathrm{g} / \mathrm{cm}^{3}\right)$ & $\begin{array}{l}\text { carbon } \\
\text { plies }\end{array}$ & $\begin{array}{l}\text { fiber } \\
\text { content }\end{array}$ & & $\left(\mathrm{g} / \mathrm{cm}^{3}\right)$ & $\begin{array}{l}\text { glass } \\
\text { plies }\end{array}$ & $\begin{array}{l}\text { fiber } \\
\text { content }\end{array}$ \\
\hline CARBON F. & 1.83 & & & GLASS F. & 2.50 & & \\
\hline EPOXY R. & 1.18 & & & G FRP No. 1 & 1.23 & 2 & $7.5 \%$ \\
\hline C FRP No. 1 & 1.20 & 1 & $3.7 \%$ & 2 & 1.25 & 4 & $8.1 \%$ \\
\hline 2 & 1.21 & 2 & $6.7 \%$ & 3 & 1.31 & 8 & $17.5 \%$ \\
\hline 3 & 1.22 & 4 & $8.0 \%$ & 4 & 1.43 & 16 & $31.8 \%$ \\
\hline 4 & 1.28 & 8 & $21.3 \%$ & 5 & 1.51 & 32 & $40.4 \%$ \\
\hline
\end{tabular}

あげて測定した。GFRP では，ガラスクロスの枚数によ らずに測定できるが，カーボンクロスの枚数は，図 5 ， 7 から10枚以内に制限される。

カーボンクロスを用いた試料において，䄉維重量含有 率の低く，むらのある場合，クロスの武料内の位㯰によ ク、マイクロ波の透過舅が巽なってくる。実騃に用いた 装䁂では，ク口スの位置が $1 \mathrm{~cm}$ ずれると，試料の透過損 失は約 $10 \mu \mathrm{W}$ 違いを生ずる。しかし，位置と透過損失 の関係は直楾関係にならず，威3に示した定在波と相似 の波形になる。すなわち、クロスの位湍の違いにより， マイクロ波の反射波の掁幅と位相が違ってくるためであ る。FRPの製作に扔ける脱泡の影謷については，カー ボンクロスでは，クロス1枚の透逼揁失が大きいので影 整は小さい，ガラスクロスでは，ク口ス 1 枚の透過損失 が非常に小さいので影辢は大きく，枚数の多い陚料では 逆に透過損失が大きくなる。

\section{4. 結論}

ガラスタロス，カーボンクロスを用いて F R P 製作 し，その瀻維含有赫について，マイクロ波を用いての非 破填睍定法について検封し，次の結諭を得た。

1) GFRPでは，そのマイク口波の透過損失は緎維重 䁷含有率の增加に従い减少する。そしてその减少の度合 はCFRPの的1/40 と小さい。

2) CFRP では，マイクロ波の透過損失は，䄉維重量 含有皁の增加に従认增加寸る。そしてその增加の度合が 大きく，カーポンクロス10枚以上では測定できない。

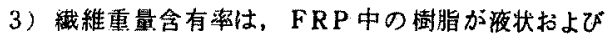
固体の雨方において測定することができた。さらにFRP 中の樹脂の硬化渦程も同時に測定することができた。た だし，カーボンクロスが多く入った試料では，樹脂の状 態変化による透過量の変化は小さい。

本研究は昭和 49 年 5 月, 日本材料学会春季大会にお いて発表した。

\section{文南}

1) 植村益次, 阿部慎蔵；第 5 回複合材料シンポシウム 要旨集, p. 199 (1972)

2）四方田重昭，小野昌孝，牧広; 材料， 23，1080 (1974)

3) 小林繁夫；第 5 [回複合材料シンボジウム要旨集， p. 161 (1972) 山脇弘一, 植村益次; 東大宇宙航空研究所報告, 7, No. 2, 1 (1971)

Hashin. Z. and B.W. Rosen ; J. Appl. Mech., 31. No. 2, p. 223 ( 1964)

4) J.K.Gilham and A.F. Lewis ; J.Polym. Sci., C 6. 125 (1964)

5）小儿文一，太田正光；「マイク口波，ミ引波测定」， コ口ナ社, p. 68, p. $300(1969)$

6）森本和久，中野明长波章；工業化学，67， 848(1970)

C.F.Feazel ; J. Polym. Sci., 15, 351 (1957)

7) R. Botsco ; Plastic World, No.5, 1 (1969)

8）飯口真一, 井上昭, 提坂秀樹; 第 2 回FRPシン ボジウム要旨集， p. 31（1967） 